\title{
Seeking the improvement of effectiveness and efficiency in the dual patient approach
}

AUTHORS: C. Vasconcelos ${ }^{1}$, JA.Santos Silva ${ }^{1}$, J.Freixo ${ }^{1}$, F.Pessoa ${ }^{1}$, I.Carrera ${ }^{2}$, M.Conde ${ }^{2}$, JM.Fernández ${ }^{2}$, Mạ.Álvarez ${ }^{2}$,L.Bugallo², F.Otero2, M.Serrano", "TRANS-NILD-GROUP"

TRANS-NILD-GROUP: (1): A.Ferreira, K.Hoffmeister, S.Rodrigues, S.Cardoso, A.Tavares, C.Coutinho, A.Seabra; (2): C.Pereiro, MํJ.Paramo, N.Melero, T.Rodríguez, M.Paramo, JM.Olivares, Mํㅡ.C. García-Mahía, Mํ..Vidal, Mํㅡ.Marcos, S.Gómez, R.Gómez, G.Méndez; A.Bermúdez,

CENTERS: (1):DICAD, ARS Norte, Porto, Portugal

(2):SERGAS, Sergas, Galicia, Spain

Contact adress: carlos.vasconcelos@arsnorte.min-saude.pt indalecio.carrera@asoc-aclad.es

\section{Objectives:}

Evaluate the effectiveness and efficiency of the programs with LAl antipsychotics in dual patient approach.

\section{Background:}

Care of addicted patients with an associated mental disorder is a challenge for the networks of Addiction and Mental Health, specially in patients with a severe mental disorder (1)(2). The assistance model, must be comprehensive and integrated, with flexible treatment programs with long-acting injectable (LAI) antipsychotics, multidisciplinary teams, located in the addiction centers.

In Galicia, this is a project coordinated by local Psychiatry services and managed by hospital pharmacy, bringing significant cost savings (3).

\section{Materials and Methods:}

This is an open, observational, indication-prescription study (4), approved by Ethical Commissions from Galicia and Porto.

Sample: 172 patients, 32 in Portuguese centers, 140 in the Galician network: 102 from Corunha Addiction Center, where this program was introduced in Oct/2014; due to this sample's size, the result analysis is mainly based on Corunha results.

Instruments: Medical records and CGI and SMARTS scales (5).

\section{Results and Conclusions:}

Only 7 drop-out cases (3.1\%) and 83,3\% of abstinence (FIG. 1).

The Portuguese network use older LAls, prescribed mostly for psychotic spectrum, while in Galician network this happens with LAI-PLP (FIG. 2) and the "off-label" use (FIG. 3) is higher with LAIARP, in comorbid personality disorders (cluster B).

$90 \%$ of the patients treated with LAI-ARP don't have side effects, compared to $25 \%$ of LAI-PLP (FIG. 4).

Patients, significantly reduce their readmissions in acute psychiatric units and the frequency of hospital emergency services (FIG. 5).

The annual cost of the pharmacological treatment of dual patients in Coruña center (with a poly-pharmacy ratio $>85 \%$ ), amounts to $8,759 €$ /year, but the annual cost specific of LAl treatment is less than their hospitalization (FIG. 6).

Our results support the effectiveness and efficiency of LAls programs applied from addiction centers, with a comprehensive and integrated approach within the health network, to avoid duplication and the so-called "revolving door syndrome".

\section{Bibliography:}

(1) $\mathrm{M}^{\mathrm{o}}$ Sanidad, Servicios Sociales e Igualdad: Estrategia para el abordaje de la cronicidad en SNS. Ed. M $^{\circ}$ Sanidad, Madrid, 2012.

(2) Haro G, Bobes J, Casas M, et als. Tratado sobre Patología Dual. Reintegrando la salud mental. Barcelona. MRA Ediciones, 2010.

(3) Vázquez-Mourelle, $\mathrm{R}$ et als: Eficiencia del programa de seguimiento farmacoterapéutico de antipsicóticos parenterales de acción prolongada en área sanitaria de Santiago Compostela. Gaceta Sanitaria 30(21): 73-76, 2016.

(4) Serrano, M; Ferreira, A ; Carrera, I; Santos-Silva, J, et als: Avaliación multidimensional dos enfermos a tratamento nas redes asistenciais de adiccións de Galicia e norte de Portugal (proyecto “Gali-Port"). Aprobado por CEICG y AEMPS, 2017.

(5) CIBERSAM: Banco de instrumentos para la práctica de la Psiquiatría Clinica. Ed. Univ. Oviedo, 2014.

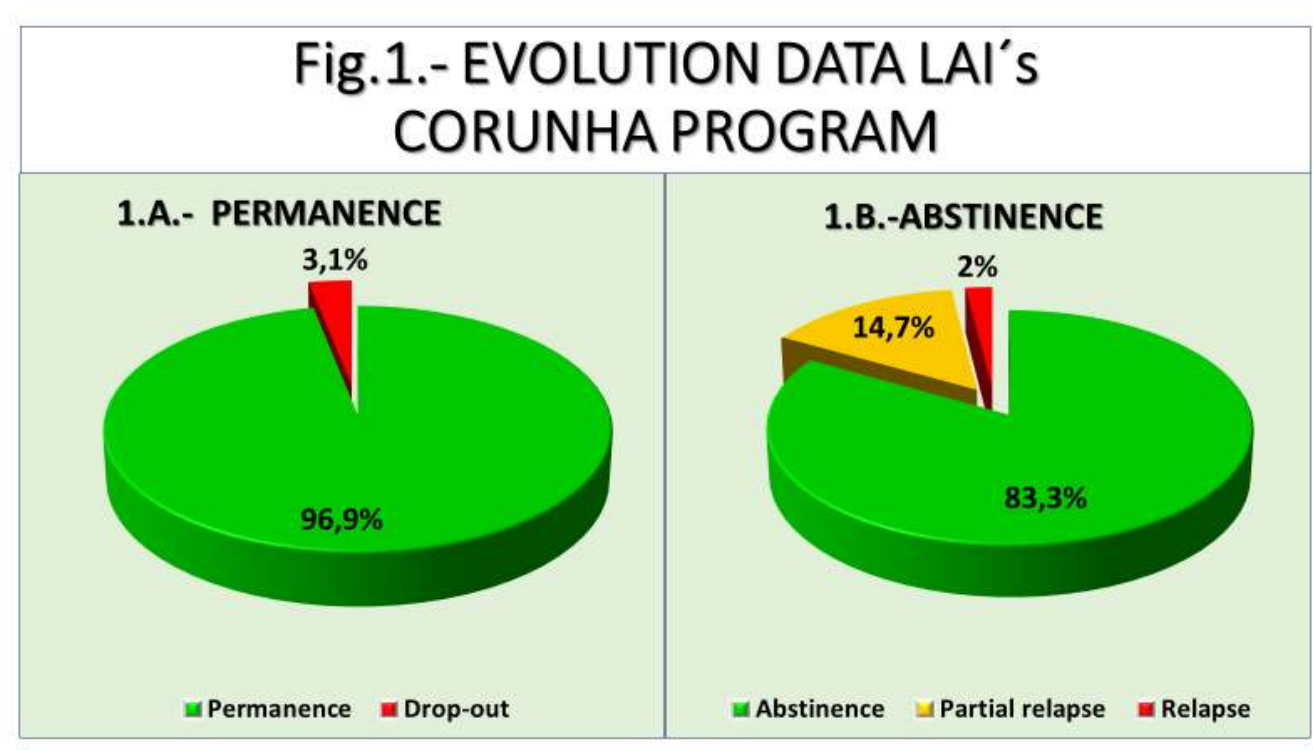

Fig.2.- LAI's DISTRIBUTION (2014)

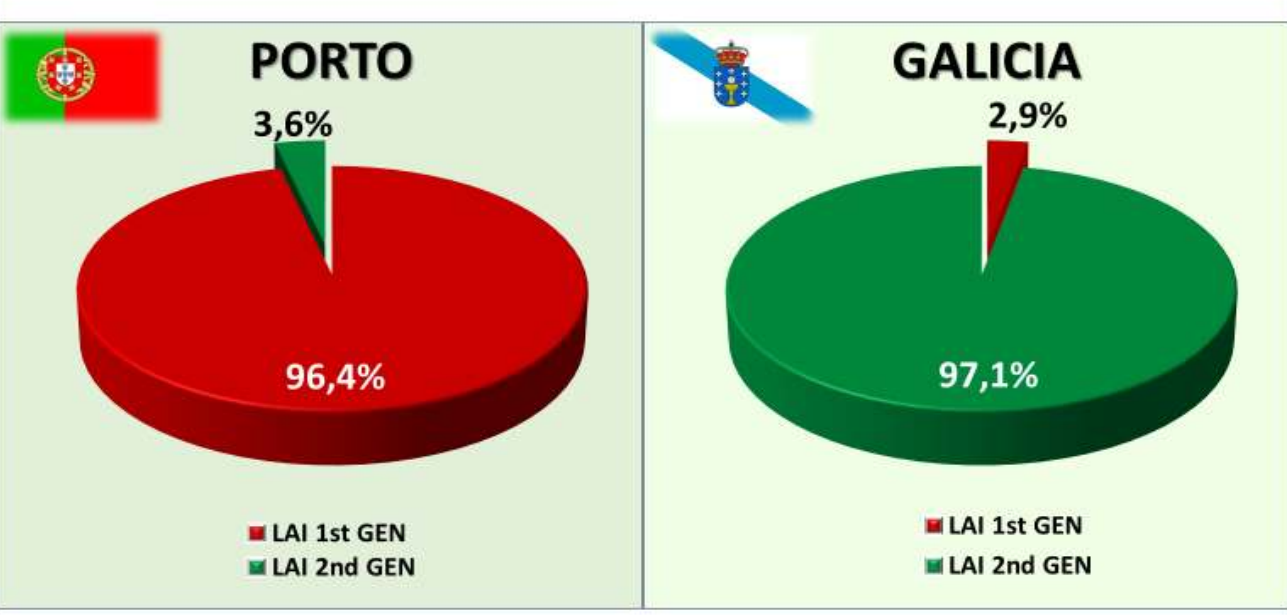

Fig 3.- PSYCHIATRIC ASSOCIATED DISORDERS

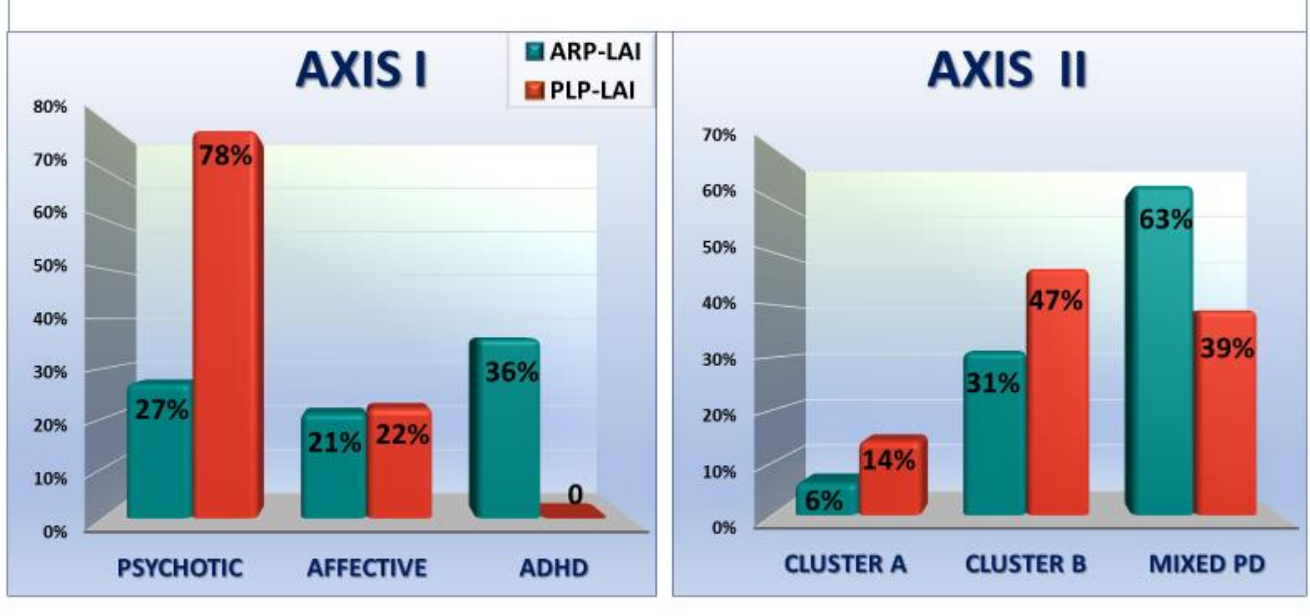

Fig. 4.- SE \& TREATMENT INTERFERENCE

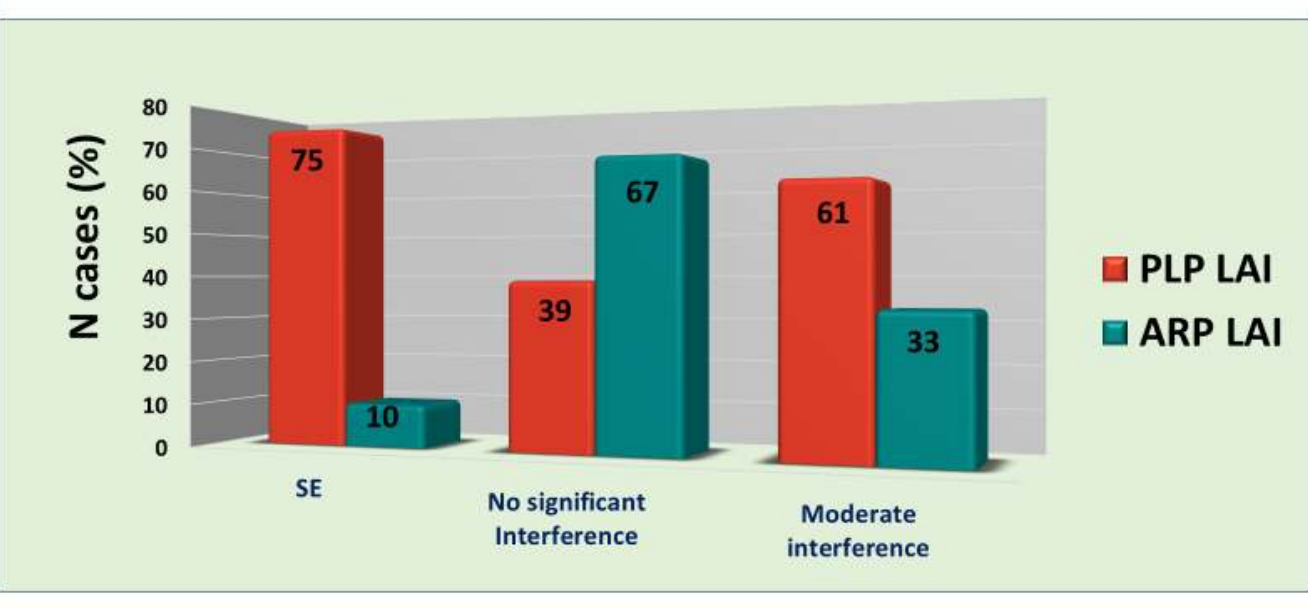

Fig. 5.- USE OF HEALTH RESOURES

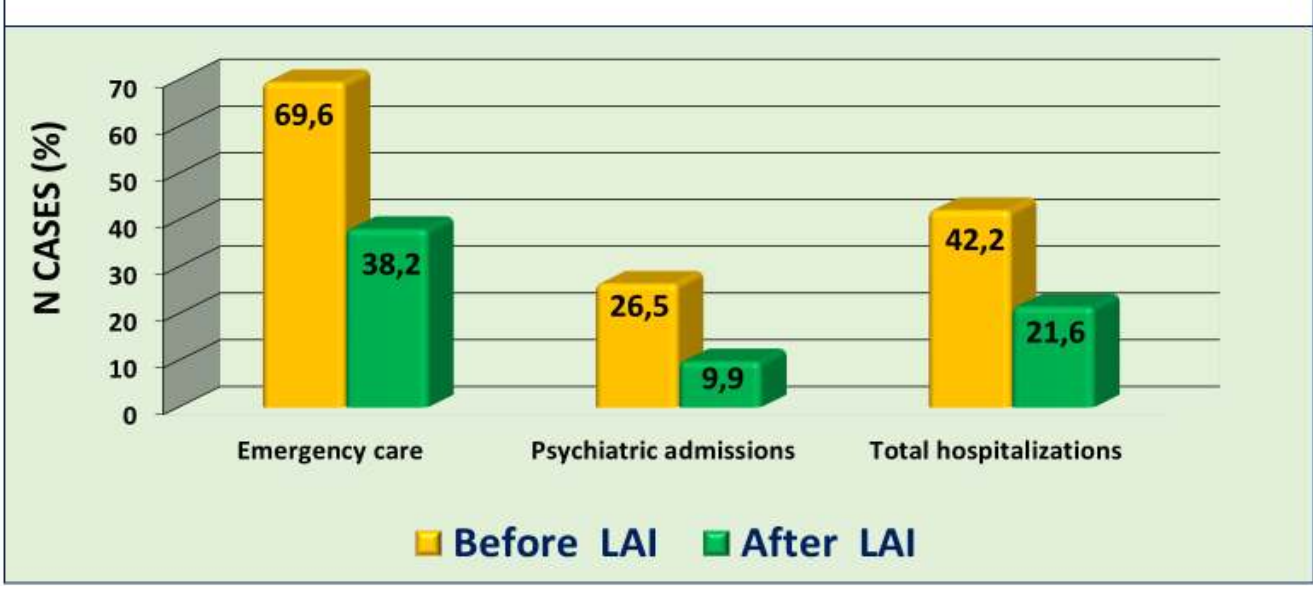

Fig. 6.- ANNUAL TREATMENT COSTS

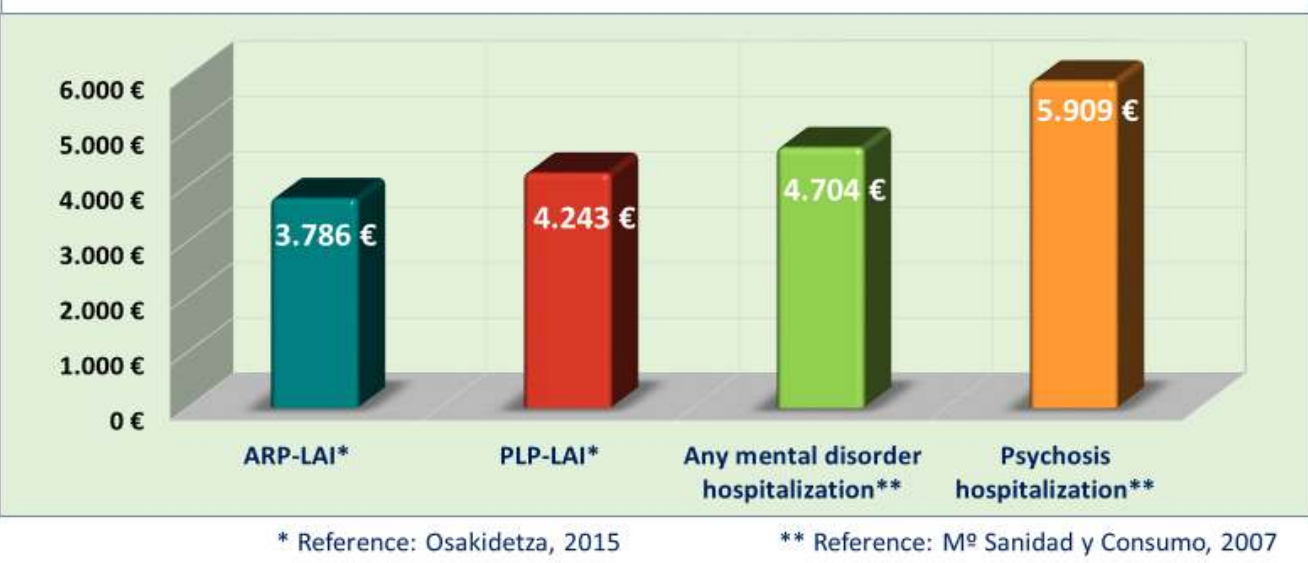

